\title{
O empreendedorismo e a inovação transformados em modelos de sucesso em uma instituição de ensino superior de Alagoas
}

\author{
Érica A. da Silva ${ }^{1,2}$, Jacqueline F. da Silva ${ }^{1}$, Joana M. L. Costa ${ }^{1}$, Carlos W. F. V. \\ de Araújo ${ }^{1}$, Fábio D. de O. Albuquerque ${ }^{1}$ \\ ${ }^{1}$ Faculdade Maurício de Nassau \\ Maceió - AL - Brasil \\ ${ }^{2}$ Centro de Estudos e Sistemas Avançados do Recife (CESAR) \\ Recife - PE - Brasil \\ \{erica.acioli,jacfel,joannaliins, carlos.vasconcelos.wfa, fabiosk881\}@gma

\begin{abstract}
The impulse of Information and Communication Technologies in the 21st century, favored for increased academic interest and the amount of research centers aimed in entrepreneurship in Brazil. Gradually the digital entrepreneurship has gotten a special highlight on higher education institutions allowing the development of skills and abilities, transforming ideas in possible projects to be executed. This article aims to present through a qualitative research, case studies performed in Alagoas, besides some results about entrepreneurship experience coupled with applied technology in a dynamic and challenging context proposed by College Mauricio of Nassau.
\end{abstract}

Keyword: Technology, Education, Entrepreneurship, Innovation, Startups.

Resumo - O impulso das Tecnologias de Informação e Comunicação no século XXI, favoreceu para o aumento do interesse acadêmico e a quantidade de centros de pesquisas direcionados ao empreendedorismo no Brasil. Aos poucos o empreendedorismo digital tem obtido um destaque especial nas Instituições de Ensino Superior possibilitando o desenvolvimento de competências e habilidades, transformando ideias em projetos possíveis de serem executados. Esse trabalho visa apresentar por meio de um estudo qualitativo, casos de sucesso realizados em Alagoas, além de alguns resultados da experiência do empreendedorismo aliado à tecnologia aplicado em um contexto dinâmico e desafiador proposto pela faculdade Maurício de Nassau.

Palavras-chave: Tecnologia, Educação, Empreendedorismo, Inovação, Startups.

\section{Introdução}

O papel das instituições de ensino superior e a sua ligação com o universo do trabalho, tornam central a reflexão em torno da importância da educação voltada ao empreendedorismo e ao seu impacto na dotação de um perfil de empregabilidade 
adequado para os jovens com qualificações superiores. A este nível entende-se que o empreendedorismo coloca novos e importantes desafios às Universidades que passam pela (re)definição das suas estratégias e pela adoção de mecanismos e de instrumentos úteis para o despertar de um "espírito" empreendedor e de inovação nos seus estudantes.

Para ilustrar esta importância, o presente artigo procura explorar os resultados obtidos com essa experiência de empreendedorismo e inovação aplicada aos jovens dos cursos de Tecnologia da Informação da Faculdade Maurício de Nassau, por meio de dois Seminários realizados nesta instituição, ocorridos no primeiro semestre de 2014 e 2015 , destacando de modo particular o empreendedorismo digital. A partir da abordagem aqui apresentada, ambiciona-se perspectivar o papel do ensino superior para $o$ desenvolvimento do potencial empreendedor dos indivíduos, bem como avaliar o impacto de determinadas atividades formativas (formais e não formais), em contexto acadêmico, para a aquisição de competências que contribuam para o reforço da pesquisa, inovação e empregabilidade.

A promoção da cultura do empreendedorismo inovador nos ambientes acadêmicos apresenta-se como uma alternativa e um desafio para as Instituições de Ensino Superior (IES) na adoção de mecanismos estratégicos que conduzam ao processo de gerar nas pessoas condições para que estas desenvolvam competências e habilidades que estimulem e identifiquem oportunidades e interesses, transformando ideias e visões em projetos possíveis de serem executados.

Esta pesquisa visa destacar a importância do referido programa e seus mecanismos de atuação na Faculdade, cujas ações estão voltadas para a formação de uma cultura empreendedora e de inovação, apoiando e subsidiando a sua comunidade interna e externa com o objetivo de estimular o espírito empreendedor e inovador.

\section{Empreendedorismo na Educação: reinventando a preparação do aluno para o mercado de trabalho}

A importância da disseminação de uma cultura empreendedora nas IES é fundamental, já que no mercado atual há uma imensa diversificação de exigências e necessidades de formação. As iniciativas inovadoras são vistas como uma maneira sensata e promissora para enfrentar os desafios do mundo, já que elas se configuram como um legítimo diferencial para as organizações que desejam se posicionar estrategicamente no mercado.

A palavra empreendedora (entrepreneur) é originada do francês no século XVI, e quer dizer aquela pessoa que assume risco e começa algo novo (DORNELAS, 2001). No entanto, eis que "apenas no século XVIII o termo passou a ser empregado para atores econômicos, entrepreneurs eram aqueles que introduziam novas técnicas agrícolas ou arriscavam seu capital na indústria” (MELO, 2008, p.72).

Schumpeter, considerado o principal teórico clássico do empreendedorismo, retoma o termo associando-o à inovação para explicar o desenvolvimento econômico. (MELO, 2008). Esse mesmo autor em 1950, refere-se à essência do empreendedorismo como sendo a percepção e a exploração de novas oportunidades, utilizando os recursos de maneira inovadora. Para ele, empreender e inovar são consequências um do outro, integrando-se totalmente. 
Foi na década de 80 que o termo empreendedorismo cresceu no campo acadêmico (internacional), em parte, estimulado pelo interesse político em torno do trabalho de David Birch, que pesquisou o papel das pequenas firmas para a geração de empregos, conseguindo assim atrair a atenção de políticos dos EUA, da Europa e Ásia que os convidaram para aconselhá-los nessa área.

Um pouco após essa época, Rushing(1990) ressaltou que a importância do estudo do empreendedorismo dá-se em função de sua contribuição à sociedade, além de estimular a inovação e o crescimento econômico. A inovação, por sua vez é o processo pelo qual empreendedores se tornam o centro propulsor da economia, exploram a mudança como uma oportunidade para um negócio ou um serviço diferente (DRUCKER, 2002). Outro fato que fez crescer o interesse popular e acadêmico sobre o empreendedorismo foi o surgimento do mercado dot.com, favorecendo assim o aumento do interesse acadêmico e a quantidade de centros de pesquisas direcionados ao empreendedorismo.

No Brasil, os cursos criados em nível superior passaram a apresentar o termo empreendedorismo para se referir à criação de novos negócios. A partir da década de 90 , tornou-se frequente "o sentido de empreendedorismo ligado à criação de empresa de base tecnológica e menos ligado ao investimento em capital ou estratégias de organização. Além disso, também surgiu com objetivos aplicativos" (MELO, 2008, p.88). Com isso, tornou-se frequente o sentido de empreendedorismo ligado à criação de empresa de base tecnológica e menos ligado ao investimento em capital ou estratégias de organização. Sendo assim, uma instituição contemporânea deverá ter entre suas atribuições mais importantes a capacidade de tornar seus alunos seres sociais, capazes de compreender seus papéis e de aplicar os conhecimentos técnicos e científicos adquiridos, além de estar em consonância com as demandas emergentes da sociedade.

Neste contexto, torna-se necessário analisar o papel da IES, que é o de gerar em seus educandos condições para que desenvolvam competências e habilidades que estimulem a identificação de oportunidades e interesses, transformando ideias e visões em projetos possíveis de serem executados.

Para tanto, é necessário incentivar a formação de futuros empreendedores por meio de disciplinas, as quais, reforcem o contexto interdisciplinar dentro das IES, criando interações entre as disciplinas de empreendedorismo, inovação e propriedade intelectual; cursos de curta duração na área de gestão, legislação e da criação de oportunidades para o exercício da iniciativa e da criatividade.

Na IES - Faculdade Maurício de Nassau (Unidade Maceió-AL) em 2014, iniciou -se um trabalho multidisciplinar dentro das matrizes curriculares nas disciplinas de tópicos integradores I e II, Projetos Integradores I e II, dos cursos de Sistemas de Informação e de Análise e Desenvolvimento de Sistemas, respectivamente, como um projeto integrador de empreendedorismo com uso de conhecimentos e habilidades tecnológicas, sendo trabalhado em sala de aula com os docentes e discentes. Buscando explorar as experiências de mercado local e nacional do corpo acadêmico trazendo para o ambiente da academia, necessidades e vulnerabilidades do cenário atual de Tecnologias de Informação e Comunicação (TIC), saindo do modelo convencional na qual a disciplina de empreendedorismo é tratada de forma isolada e não multidisciplinar. 
Estas matrizes curriculares, proporcionam o aprendizado em Gestão e Tecnologia da Informação, além de Análise e Desenvolvimento de Sistemas. Para um melhor resultado na absorção do conhecimento nas disciplinas ofertadas e a sua prática, a Faculdade conta com a parceria de docentes e monitores, trabalhando com a integração destes conhecimentos adquiridos, gerando desse modo uma formação prática e um espírito empreendedor em seus alunos, processo que ocorre deste a entrada do aluno até à conclusão do seu curso.

\section{Startups na Educação: trabalhando o empreendedorismo e inovação dentro da IES aproximando o corpo discente do mercado de trabalho}

Com essa iniciativa da I Semana prática de Empreendedorismo e Inovação, foi possível atrair a participação de 200 estudantes de vários cursos, dando oportunidades para os alunos de diferentes áreas do conhecimento começarem a trabalhar na modalidade de fábrica de software e formarem equipes multidisciplinares, unindo os cursos de: Tecnologia, Administração, Publicidade, Gastronomia, Design, Recursos Humanos, Ciências contábeis, bem como os alunos do Pronatec para essa troca de experiências.

O empreendedorismo tecnológico está tendo uma boa abrangência no Estado de Alagoas com a criação do polo tecnológico, cujo objetivo é de incubar, fomentar e atrair empresas do setor das TIC para o desenvolvimento de tecnologias e transmissão do conhecimento da academia para o setor produtivo, integrando essas iniciativas acadêmicas com indústria e governo proporcionando ações conjuntas na elaboração de políticas voltadas a tecnologia e inovação.

Outras iniciativas também têm surgido com o apoio do SEBRAE, contemplando essa área de empreendedorismo digital, proporcionando ações de estímulo a startups e também esforços transversais, que incentivem e valorizem o uso das TIC como ferramenta de competitividade e agregação de valor aos demais setores da economia.

O termo startup surgiu com as empresas norte-americanas que cresceram rapidamente a partir de modelos de negócio fáceis de serem geridos e expandidos em larga escala e começou a ser popularizado nos anos 90 quando ocorreu a primeira grande "bolha da internet". Sendo assim, boa parte das empresas startups surgiram no Vale do Silício (Silicon Valley), local de onde nasceram empresas como: Google, Facebook, Microsoft, Apple, entre tantas outras.

No Brasil, as primeiras empresas a seguirem esse modelo iniciaram seus trabalhos no começo do século XXI, no entanto, foi a partir de 2010 que este segmento apresentou um rápido crescimento proporcionando o surgimento de vários polos de formação e expansão de startups pelas diferentes regiões do país.

Em Alagoas surgiu, no ano de 2012, o Sururu Valley, cujo nome foi inspirado em um marisco típico da culinária local e em associação ao Silicon Valley. Dentre as diferentes startups que integram o grupo, faz-se necessário destacar dois casos de sucesso. O primeiro deles é a empresa Hand Talk, desenvolvedora de um aplicativo de mesmo nome, que traduz palavras e frases para a Língua Brasileira de Sinais (LIBRAS) facilitando a comunicação com os Surdos e conquistando diversos prêmios nacionais e internacionais, e o segundo deles é o aplicativo Meu Tutor, criado em 2014, cuja 
proposta principal é facilitar a preparação para o Exame Nacional do Ensino Médio (ENEM), recebendo também premiações locais e nacionais.

Diante de tantos outros cases de sucesso, a IES Maurício de Nassau por meio da sua coordenação de TI e demais cursos, com apoio da instituição, conseguiu reunir diferentes parceiros para a realização de seu I Seminário de Empreendedorismo e Inovação, aliando assim as atividades acadêmicas ao que de melhor tem surgido no mercado de trabalho no que tange a empreendedorismo, a tecnologia e a inovação.

Da primeira edição do evento, duas ideias sobressaíram das demais, a primeira foi o "Na Palma da Mão", ideia formada e apresentada por alunos do Pronatec, no qual abordou o mercado turístico de Alagoas, e a segunda, o aplicativo "Lugar Ideal", formado por alunos do quinto período do curso de Sistemas de Informação, onde, por meio de uma conversa entre amigos, surgiu a ideia de criar um aplicativo voltado para o entretenimento adulto, e que, por meio deste, fosse possível descobrir os melhores e mais próximos motéis com as melhores promoções tanto do mercado moteleiro, quanto do mercado de sextoys. A segunda ideia conseguiu seguir adiante, desenvolvendo a fase beta da aplicação e a disponibilizando para o mercado, participando também de eventos na área de startup como o COALTI - Congresso de Tecnologia, a Campus Party Recife 3 e o Demoday da Aceleradora 21212 no Rio de Janeiro.

O sucesso obtido através do evento foi tão grande que este tornou-se um evento oficial da instituição e em sua segunda edição, aberta à comunidade, trouxe duas propostas bem interessantes e distintas, a equipe que ficou em primeiro lugar foi composta por alunos do ensino médio oriundos da cidade de Boca da Mata (AL) da Escola Cenecista, cuja proposta foi a criação de um jogo chamado BigSpace para auxílio de crianças de 4 a 12 anos que possuem déficit de atenção. Já a equipe que ficou em segundo lugar, foi composta por alunos do primeiro período do curso de Análise e Desenvolvimento de Sistemas, apresentando a ideia de um aplicativo voltado para um treinamento vocal, abrangendo um público que gostaria de ter um auxílio para aprender a cantar.

Tanto no primeiro evento quanto no segundo, os alunos tiveram a oportunidade de receber treinamento de modelo de negócios com o Canvas $^{1}$, Pitch ${ }^{2}$ e de desenvolvimento de ideias. As cinco equipes que se destacaram foram avaliadas por uma comissão formada por representantes do Governo do Estado de Alagoas (ITEC e Seplande), Sebrae, UFAL, IFAL, Coalti, SECTI (Secretaria do Estado de Ciência, Tecnologia e Inovação), ASSESPRO (Associoções das Empresas Brasileiras de Tecnologia da Informação), cases de sucesso do Estado com representantes da Hand Talk, Kloset e IlhaSoft, além de representantes do CRA (Conselho Regional de Administração) e da Liga dos Administradores, professores do SENAI/EBEP e investidores Anjo, sendo avaliados nos critérios de melhor ideia, forma de aplicação e vendas. Como premiação, os dois primeiros lugares receberam apoio da IES, do Sebrae

\footnotetext{
${ }^{1}$ É uma ferramenta de gerenciamento estratégico, que permite desenvolver e esboçar modelos de negócio novos ou existentes.

2 É uma expressão inglesa que pretende referir-se a uma curta apresentação de vendas. Tão curta e objetiva que pode ser feita durante uma "viagem" de elevador.
} 
e de um mentor ${ }^{3}$ participante do evento, para auxílio no desenvolvimento da ideia e aplicação da mesma em seu mercado.

\section{Analisando o efeito empreendedor gerado nos alunos a partir da proposta do Seminário de Empreendedorismo e Inovação dentro da academia}

Os eventos de empreendedorismo e inovação realizados no primeiro semestre de 2014 e 2105 na Faculdade Maurício de Nassau tiveram como objetivo principal apresentar os discentes ao mercado de trabalho durante seu período de formação, proporcionando a estes a oportunidade de criar e participar de uma fábrica de softwares dentro da Faculdade, podendo desenvolver seus projetos com a mentoria dos docentes e de parceiros advindos do mercado.

De acordo com Jobs (2011), as grandes criações resultam do amadurecimento de uma longa pesquisa, do exercício de pensar sobre, e, sobretudo, do ambiente. Baseados nessa fala, a academia auxilia aos participantes a estudar o ambiente empreendedor e, principalmente, o nicho de mercado que aplicará sua ideia, fomentando a multidisciplinaridade e a inovação por meio do empreendedorismo, sinalizando aos acadêmicos a importância do estudo "além do que se vê" fazendo-lhes "sair da zona de conforto".

Diante dessa experiência focada em empreendedorismo e inovação foi possível perceber também, o crescimento das notas dos alunos e seu engajamento nos trabalhos apresentados, já que o conteúdo transmitido em sala de aula está sendo aplicado de forma prática. Essa mudança de postura, fez com que a apresentação de seminários por parte dos discentes passasse a ser mais formal e dinâmica, melhorando também sua desenvoltura quanto à prática da negociação e do falar em público.

Para melhor compreender o grau de importância da participação dos alunos em eventos de empreendedorismo e inovação promovidos pela Faculdade Maurício de Nassau e que contribuições esses eventos têm proporcionado na qualificação e profissionalização de seus alunos, foi aplicado um questionário semiestruturado online para 18 alunos, de diferentes períodos que participaram desses eventos em 2014 e 2015.

Ao ser realizada uma análise de conteúdos mediante a fala desses alunos, foi possível destacar dois tópicos, sendo retratados respectivamente nos quadros 1 e 2 nesse referido artigo, sendo eles "O potencial das tecnologias no desenvolvimento de projetos" e "A relação das tecnologias e o sucesso do empreendedor" e, a partir deles foi possível elencar categorias como: agilidade, desenvolvimento de novas ideias, uso de tecnologias como solução de problemas, visão empreendedora, conhecimento de regras de mercado, trazendo todo esse aprendizado para o fortalecimento de um bem coletivo.

Questionados sobre a influência da tecnologia para acelerar o desenvolvimento de ideias e projetos, a maioria dos alunos vislumbraram o potencial das tecnologias para divulgar as ideias que estão desenvolvendo, destacando conceitos como agilidade, divulgação e o crescimento das possibilidades ao desenvolver um trabalho coletivo. Essas questões remetem ao senso comum, mas são visões abertas que favorecem o desenvolvimento de projetos, entre outras questões, conforme quadro 1 a seguir:

\footnotetext{
${ }^{3}$ Pessoa designada a assessorar uma pessoa ou um grupo para o desenvolvimento de sua ideia.
} 
CBIE-LACLO 2015

Anais do XXI Workshop de Informática na Escola (WIE 2015)

\section{Quadro 1 - 0 potencial das tecnologias no desenvolvimento de projetos}

\begin{tabular}{|c|c|c|}
\hline Cód. & Resposta do(a) aluno(a) & Comentário \\
\hline A1 & Com testes e desenvolvimento ágil das mesmas. & $\begin{array}{l}\text { Destaque para a categoria } \\
\text { Agilidade }\end{array}$ \\
\hline $\mathrm{A} 2$ & $\begin{array}{l}\text { A tecnologia tem a facilidade de unir várias ideias no } \\
\text { desenvolvimento, que inova ou cria projetos. Atualmente, não } \\
\text { vemos esse problema em unir a ideia de "um" e transmitir para } \\
\text { "outros", ou seja, equipe. Acelerar seu negócio, tem uma ótima } \\
\text { ferramenta, chamada tecnologia. }\end{array}$ & $\begin{array}{l}\text { Nesse item o foco é } \\
\text { direcionado para o } \\
\text { desenvolvimento de novas } \\
\text { ideias e para o trabalho } \\
\text { coletivo. }\end{array}$ \\
\hline A3 & $\begin{array}{l}\text { A tecnologia é a maneira mais rápida de alcançar pessoas. Desta } \\
\text { forma conseguimos ter uma gama muito grande de jovens e } \\
\text { adultos. Tornando a disseminação das informações com mais } \\
\text { contundência. }\end{array}$ & $\begin{array}{l}\text { A categoria Agilidade e a } \\
\text { disseminação de } \\
\text { informações são o destaque } \\
\text { nessa fala. }\end{array}$ \\
\hline A5 & $\begin{array}{l}\text { Por exemplo a divulgação de uma ideia nova e bem mais rápido } \\
\text { hoje com a ajuda digital }\end{array}$ & $\begin{array}{l}\text { Destaque para a categoria } \\
\text { Agilidade }\end{array}$ \\
\hline A6 & $\begin{array}{l}\text { através de soluções tecnológicas, o processo de desenvolvimento } \\
\text { de ideias e projetos fica muito mais viável. }\end{array}$ & $\begin{array}{l}\text { O que se destaca é o uso da } \\
\text { tecnologia } \\
\text { desenvolvimento } \\
\text { projetos. }\end{array}$ \\
\hline A10 & $\begin{array}{l}\text { Com o conhecimento da tecnologia de informação encontramos } \\
\text { soluções para diversos problemas existentes no dia a dia, seja } \\
\text { pessoal ou não. Esse conhecimento nos faz enxergar o quanto as } \\
\text { nossas limitações podem ser supridas por ela. }\end{array}$ & $\begin{array}{l}\text { Destaque para o uso de } \\
\text { tecnologias na solução de } \\
\text { problemas. }\end{array}$ \\
\hline A11 & $\begin{array}{l}\text { a tecnologia tem sido considerada como um meio e não fim. Só } \\
\text { mais recentemente é que ela se tornou um produto final. Embora } \\
\text { contraditória à primeira vista, esta afirmação é muito útil quando } \\
\text { pensamos em empreendedores e consumidores. Pois seu uso é o } \\
\text { que acaba determinado quem somos nesta relação. Se } \\
\text { consumimos tecnologia como fim nela mesma, somos } \\
\text { consumidores, mas se a utilizamos para satisfazer outras } \\
\text { necessidades, tanto nossas quanto de terceiros, já passamos a vê- } \\
\text { la como empreendedores. }\end{array}$ & $\begin{array}{l}\text { Destaque para o uso de } \\
\text { tecnologias na solução de } \\
\text { problemas, de forma } \\
\text { inovadora, pensando no bem } \\
\text { coletivo. }\end{array}$ \\
\hline A15 & $\begin{array}{l}\text { Através da agilidade do ciclo de informação que a mesma é } \\
\text { capaz de proporcionar; }\end{array}$ & $\begin{array}{l}\text { Destaque para a categoria } \\
\text { Agilidade }\end{array}$ \\
\hline
\end{tabular}

Fonte: Dados da pesquisa (2015).

Buscando refletir sobre o potencial das tecnologias no âmbito empresarial, com foco no empreendedorismo, buscou-se compreender como os alunos avaliam a importância do conhecimento do potencial de uma determinada tecnologia e como esse fato contribui na formação de um empreendedor um sucesso, elencando repostas que corroboram as afirmativas anteriores e são unânimes em reconhecer o potencial das tecnologias, contudo em relação ao sucesso do empreendedor. 
Quadro 2 - A relação das tecnologias e o sucesso do empreendedor

\begin{tabular}{|c|c|c|}
\hline Cód. & Resposta do(a) aluno(a) & Comentário \\
\hline $\mathrm{A} 2$ & $\begin{array}{l}\text { Ter o conhecimento, o sucesso vem logo em seguida. Saber } \\
\text { administrar seus conhecimentos, sabendo como utilizar. } \\
\text { Um negócio pequeno pode se tornar gigantesco. A } \\
\text { tecnologia é a base. }\end{array}$ & $\begin{array}{l}\text { Valorização do potencial da } \\
\text { tecnologia e do conhecimento }\end{array}$ \\
\hline A 3 & $\begin{array}{l}\text { Conhecer bem uma tecnologia não torna um empreendedor } \\
\text { de sucesso. Mas ter conhecimento o deixa no caminho } \\
\text { certo }\end{array}$ & $\begin{array}{l}\text { Destaque para a valorização do } \\
\text { conhecimento e reconhecimento de } \\
\text { que a tecnologia não é um fim em } \\
\text { si mesmo }\end{array}$ \\
\hline A4 & $\begin{array}{l}\text { Para ter sucesso, deve-se conhecer o mercado que está } \\
\text { entrando. Seus concorrentes, onde se deve melhorar etc. O } \\
\text { sucesso vem do conhecimento de campo que se tem, afinal } \\
\text { uma guerra só é vencida, quando se conhece os } \\
\text { adversários. }\end{array}$ & $\begin{array}{l}\text { Destaque para o conhecimento das } \\
\text { regras do mercado e dos potenciais } \\
\text { concorrentes. }\end{array}$ \\
\hline A9 & $\begin{array}{l}\text { Com o conhecimento da tecnologia do que você realmente } \\
\text { que fazer, exemplo: Um jogo. Você poderá realizar o } \\
\text { projeto com mais eficiência e qualidade }\end{array}$ & $\begin{array}{l}\text { Foco no conhecimento e na } \\
\text { capacidade de aliar as ideias ao } \\
\text { conhecimento do potencial dos } \\
\text { recursos disponíveis. }\end{array}$ \\
\hline A10 & $\begin{array}{l}\text { O conhecimento apurado da tecnologia da informação, faz } \\
\text { ver o quanto os limites pessoais podem ser supridos pela } \\
\text { tecnologia em ascensão. Ou seja, a tecnologia em si já é } \\
\text { um desenvolvimento mais evoluído de qualquer coisa já } \\
\text { criado e seu surgimento vai aos poucos primorando } \\
\text { conforme as necessidade humana e trazendo cada vez mais } \\
\text { conforto as pessoas }\end{array}$ & $\begin{array}{l}\text { Valorização da tecnologia em } \\
\text { detrimento de quaisquer outros } \\
\text { elementos; }\end{array}$ \\
\hline A11 & $\begin{array}{l}\text { Empreendedores de sucesso são antes de tudo pessoas que } \\
\text { sabem o que querem alcançar. Assim sendo, não medem } \\
\text { esforços para se cercarem da tecnologia certa na hora que } \\
\text { precisam. Um destes esforços é aprender sobre a tecnologia } \\
\text { que utilizam. É verdade que, como empreendedores não } \\
\text { precisamos ser especialistas em cada pequena } \\
\text { tecnologia que nos cerca, mas precisamos saber o } \\
\text { suficiente para executarmos uma das tarefas mais } \\
\text { importantes de qualquer empreendimento: a } \\
\text { comunicação. }\end{array}$ & $\begin{array}{l}\text { Visão empreendedora. } \\
\text { Reconhece o potencial da } \\
\text { tecnologia, mas destaca os seus } \\
\text { limites e valorização da } \\
\text { comunicação. }\end{array}$ \\
\hline A13 & $\begin{array}{l}\text { Sim. Hoje em dia tudo gira em torno da tecnologia. Se faz } \\
\text { necessário um empreendedor conhecer bem essa área. } \\
\text { Até porque a tecnologia é a porta do mundo. }\end{array}$ & $\begin{array}{l}\text { Foco na tecnologia e sua relação } \\
\text { com o empreendedorismo. }\end{array}$ \\
\hline A15 & $\begin{array}{l}\text { Se ele conhece bem tanto a tecnologia quanto o propósito } \\
\text { para o qual está se aplicando ela, a combinação deve } \\
\text { atingir um conjunto de bons resultados. }\end{array}$ & $\begin{array}{l}\text { Valorização do potencial da } \\
\text { tecnologia e sua aplicabilidade no } \\
\text { desenvolvimento das ideias. }\end{array}$ \\
\hline
\end{tabular}

Fonte: Dados da pesquisa (2015).

A partir da aplicação desse questionário, foi possível perceber que essa participação dos alunos proporcionou auxílio em decisões como: áreas de trabalho a 
serem seguidas, entendimentos de assuntos discorridos em sala de aula, aplicação prática de processos aprendidos e principalmente, no entendimento do ecossistema que irão inserir-se ao término do curso.

De acordo com as falas apresentadas pelos alunos, foi possível perceber também o quão valoroso foram as contribuições da semana do empreendedorismo e da inovação na vida acadêmica deles, que enfatizaram de forma positiva os frutos desse evento. Na percepção desses discentes, foi exaltado o potencial do uso das tecnologias, a interação com demais participantes e as etapas de elaboração dos projetos, além da importância da disseminação de propostas e ideias.

\section{Considerações Finais}

As rápidas mudanças ocorridas no cenário econômico, tecnológico e social provocaram uma profunda transformação na dinâmica do mercado de trabalho, lançando assim, um grande desafio às Instituições de Ensino Superior neste século; saber aliar as tecnologias disponíveis à sua área de conhecimento, tendo como consequência uma reformulação em sua prática pedagógica.

A Faculdade Maurício de Nassau - Unidade Maceió - AL, vem buscando trazer a prática do mercado para sala de aula de forma contextualizada, com o objetivo de estimular a pró-atividade do aluno em relação a pesquisa, unindo o cenário mercadológico, a visão empreendedora e capacidade produtiva e gestora dos acadêmicos.

Mediante uma proposta mais dinâmica de apresentar o empreendedorismo digital no mundo acadêmico, tem sido possível desenvolver projetos dentro da academia em parceria com empresas incubadoras e de renome como o SEBRAE. Essas parcerias têm proporcionado o fomento de startups por meio da inserção das mesmas nos eventos acadêmicos, preparando as equipes com treinamentos, cursos e workshops, colocando os discentes em contato direto com potenciais investidores.

A partir da experiência gerada na I Semana de Empreendedorismo e Inovação, foi possível despertar não só o interesse dos alunos para o desenvolvimento e prática de ideias inovadoras, como gerar produtos voltados para alguns setores da sociedade carentes de soluções práticas para situações recorrentes de seu dia-a-dia.

Esse primeiro evento de cunho empreendedor e inovador, preparou o caminho para a geração de um segundo evento no ano de 2015, despertando novos empreendedores. $\mathrm{O}$ intuito de promover eventos desse tipo é de proporcionar aos alunos uma aprendizagem multidisciplinar e alavancar projetos de sucesso, gerando posteriormente, soluções tecnológicas desenvolvidas pelos próprios alunos com suporte dos docentes, bem como, produção de artigos científicos apresentando sua contribuição para uma sociedade melhor.

Diante dos resultados obtidos com os eventos propostos e realizados na instituição, unidos às falas dos alunos, é possível perceber a importância da motivação no desenvolvimento de aplicativos, favorecendo o desenvolvimento de pesquisas acadêmicas somadas as necessidades do mercado para o desenvolvimento de soluções tecnológicas. 


\section{Referências}

DORNELAS, J. C. A. Empreendedorismo: transformando ideias em negócios. 2. ed. Rio de Janeiro: Editora Campus, 2001.

DRUCKER, P. F. Inovação e espírito empreendedor: prática e princípios. 6 ed. São Paulo: Thompson/Pioneira, 2002.

JOBS, Steve. O estilo de liderança para uma nova geração. Ed. São Paulo: Lafonte, 2011.

MELO, Natália Máximo e. Sebrae e Empreendedorismo: origem e desenvolvimento. Dissertação de mestrado. São Carlos - SP, 2008. Disponível em: <http://www.bdtd.ufscar.br/htdocs/tedeSimplificado//tde_busca/arquivo.php?codA rquivo=2186>. Acesso em: 30 maio 2015 .

RUSHING, Francis W. Entrepreneurship and education. In: KENT, Calvin A. Entrepreneurship education: current developments. New York: Quorum Books, 1990. p. 41. Disponível em: http://www.questia.com. Acesso em: 29 de maio de 2015. 